\title{
Application of the Laws of Physical Statistics to Modelling of the Jet Milling Process
}

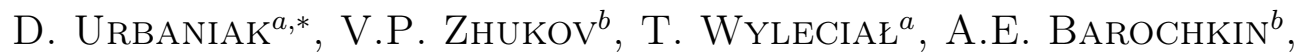 \\ H. OTWINOWSKI ${ }^{a}$ AND R. WYCZÓŁKOWSKI ${ }^{b}$ \\ ${ }^{a}$ Częstochowa University of Technology, Częstochowa, Poland \\ ${ }^{b}$ Ivanovo State Power Engineering University, Ivanovo, Russia
}

Doi: 10.12693/APhysPolA.138.156

*e-mail: urbaniak@imc.pcz.pl

\begin{abstract}
The Maxwell-Boltzmann distribution in its classic form concerns the distribution of perfect gas particles into energy levels. In the paper, it was used to describe the energy distribution of ground grains of the brittle substance as a function of grain size, which allowed describing the particle size distribution of the process product. The particle size distribution of the product was identified with the effect of the grinding process, which is an extremely important parameter for the description of the entire process. The results of calculations were presented and compared with the results of experimental analyses. The experiment was carried out at different values of thermodynamic parameters of working air, which corresponded to different values of grinding energy. Comparison of the results showed that the thesis of applying the laws of statistical physics to the description of complex industrial processes gives positive results. Numerical determination of the particle size distribution of the grinding product is an extremely desirable result of research, because it allows to avoid the tedious and time-consuming experimental determinations necessary to assess the grinding product.
\end{abstract}

topics: Maxwell-Boltzmann distribution, particle size distribution, grinding, jet milling

\section{Introduction}

Granular substances are used in many industries [1-3]. In general, the proper quality of these substances is determined by their prior grinding. The universal description of the grinding is extremely complex. Its effect depends on a large number of factors which are related to the properties of the substance, the type of mill, as well as the conditions of conducting the grinding. In general, these factors are characterized by randomness of occurrence, which further complicates the description. In these cases, statistical laws on the most likely distribution of physical quantities are often used.

Basically, the grinding description concerns either the energy necessary to carry it out, or the particle size distribution of the product. In the paper the possibility of using the physical statistics laws to predict the particle size distribution of a grinding product is analyzed. For this purpose, the Maxwell-Boltzmann distribution was used. In earlier works [4-7] it was proposed to use this law to describe the energy distribution of ground solids as a function of grain size of the product. On this basis, the particle size distribution of the silica, caustic and coking coal grinding product was modelled. In the presented work, the Maxwell-Boltzmann law was used to model the grain distribution of the jet milling product of the technical chalk.

\section{Modelling of particle size distribution using the Maxwell-Boltzmann distribution law}

The Maxwell-Boltzmann law in its classic form concerns the distribution of ideal gas molecules into various energy levels [8]:

$$
n_{i}=n \exp \left(\frac{\varepsilon_{i}-\varepsilon_{0}}{k_{\mathrm{B}} T}\right) \text {, }
$$

where $n_{i}$ is number of molecules of the $i$-th energy state, $n$ - number of molecules of ground state, $\varepsilon_{i}$ - energy of the $i$-th state, $\varepsilon_{0}$ - energy of the ground state, $k_{\mathrm{B}}-$ Boltzmann constant, $T$ - absolute temperature.

In Refs. [4-7] it has been shown that this law can also be used to describe the average energy distribution of molecules of grains of a ground solid.

Using the Maxwell-Boltzmann law to determine the grain distribution of a grinding product, it can be written

$$
R_{i}=\frac{m_{i}}{m}=\frac{\rho_{i}}{\rho} \frac{n_{i}}{n}
$$

where $R_{i}$ is cumulative grain distribution, $\rho_{i}$ grain density of the $i$-th state, $\rho$ - grain density of the basic state. Assuming that the density of the grains does not depend on the state, namely, $\rho_{i}=\rho$, the above equation takes the form:

$$
R_{i}=\frac{n_{i}}{n}=\exp \left(-\left(\varepsilon_{i}-\varepsilon_{o}\right) \frac{1}{k_{\mathrm{B}} T}\right),
$$




\section{Methodology and experimental research}

To determine the particle size distribution of the jet milling product, the energy of the grains of the $i$-th state and the basic state should be determined. Experimental studies, whose purpose was to verify the correctness of the results of numerical modelling, were carried out using a type 300 jet mill. Its maximum capacity is $300 \mathrm{~kg} / \mathrm{h}$. The main part of the mill is the grinding system, which consists of two opposing jets that are fed with compressed air (Fig. 1).

In the case of a jet mill, the energy of the ground grains is kinetic energy dependent on [9]:

$$
\dot{E}_{k s}=f\left(\dot{E}_{k p}, \dot{m}_{s}, \dot{m}_{p}\right),
$$

where $\dot{E}_{k s}$ - kinetic energy stream of the ground solid, $\dot{E}_{k p}$ - kinetic energy stream of air, $\dot{m}_{s}-$ stream of ground solid, $\dot{m}_{p}$ - air flow.

This energy is a consequence of the energy exchange between the working air and the ground grains that occurs in the accelerator tube. Knowing the value of air energy, mass stream of solids and air flow, the value of kinetic energy of grains can be determined. Air energy depends on $[9,10]$ :

$$
\dot{E}_{k p}=f\left(p_{0}, T_{0}\right),
$$

where $p_{0}$ is air pressure, $T_{0}$ - air temperature.

The energy of the $i$-th state and basic state can be determined from the thermodynamic theory of grinding [9]:

$$
\begin{aligned}
& \varepsilon_{i}=f\left(\alpha, \frac{1}{\rho}, \frac{1}{X_{i}}\right), \\
& \varepsilon_{0}=f\left(\alpha, \frac{1}{\rho}, \frac{1}{X_{\max }}\right),
\end{aligned}
$$

where $\alpha$ is energy density of surface molecules, $X_{i}$ - grain size of the $i$-th state of the grinding product, $X_{\max }$ - size of the largest grain of the grinding product (basic state).

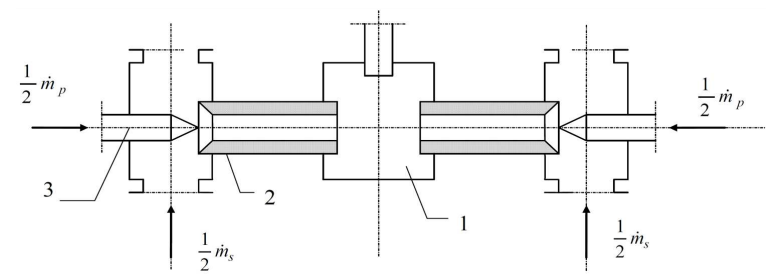

Fig. 1. Schematic of jet mill: 1 - milling chamber, 2 - accelerating tube, 3 - nozzles: $\dot{m}_{s}$ stream of ground solid, $\dot{m}_{p}-$ air flow.

TABLE I

Some physicochemical properties of technical chalk.

\begin{tabular}{c|c|c|c}
\hline \hline $\begin{array}{c}\text { Type } \\
\text { of material }\end{array}$ & $\begin{array}{c}\text { Density } \\
\rho\left[\mathrm{g} / \mathrm{cm}^{3}\right]\end{array}$ & $\begin{array}{c}\text { Mass and matter } \\
\text { equivalent } \\
M[\mathrm{~kg} / \mathrm{kmol}]\end{array}$ & $\begin{array}{c}\text { Chemical } \\
\text { composition }\end{array}$ \\
\hline $\begin{array}{c}\text { technical } \\
\text { chalk }\end{array}$ & 2.93 & 100 & $\begin{array}{c}97 \% \\
\mathrm{CaCO}_{3}\end{array}$
\end{tabular}

The value of energy density of surface molecules $\alpha$, according to the thermodynamic theory of grinding $[7,9]$, is a function of

$$
\alpha=f\left(\dot{E}_{k s}, \dot{m}_{s}\right) \text {. }
$$

Finally, the formula for the cumulative grain distribution will take the form $[5,6]$ :

$$
R_{i}=\exp \left(-\frac{6 M \alpha}{(M R) \rho T}\left(\frac{1}{X_{i}}-\frac{1}{X_{\max }}\right)\right),
$$

where $M$ - mass equivalent of the ground substance, (MR) - universal gas constant.

Technical chalk was used for experimental research. During the tests, different values of thermodynamic parameters (pressure and temperature) of the working air were used, which corresponded to different values of grinding energy. Samples of the tested material were subjected to grain analyses. Particle size distribution was determined using a Bahco pneumatic centrifuge [11].

The technical chalk properties are presented in Table I.

\section{Research results and their analysis}

Based on the presented algorithm, numerical determinations of the cumulative grain distribution of ground technical chalk were carried out. The results of numerical and laboratory determinations are presented in Figs. 2-7.

The results listed above illustrate the occurrence of significant convergence in the values of cumulative distributions of grains obtained in the laboratory and calculated according to the proposed numerical algorithm. This proves that it is possible to numerically predict the granular distribution of the product of jet grinding of brittle substances.

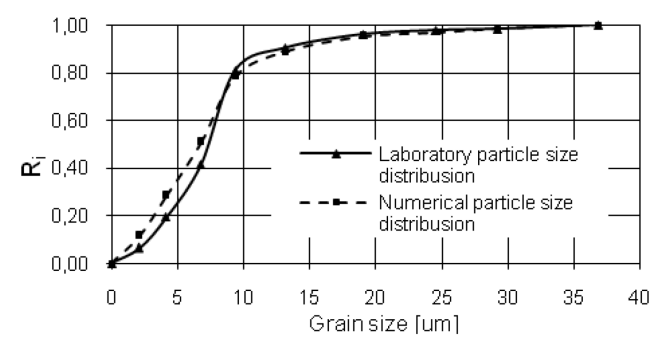

Fig. 2. Cumulative particle size distribution of grinding product technical chalk $(p=0.3 \mathrm{MPa}$, $t=13^{\circ} \mathrm{C}$ ).

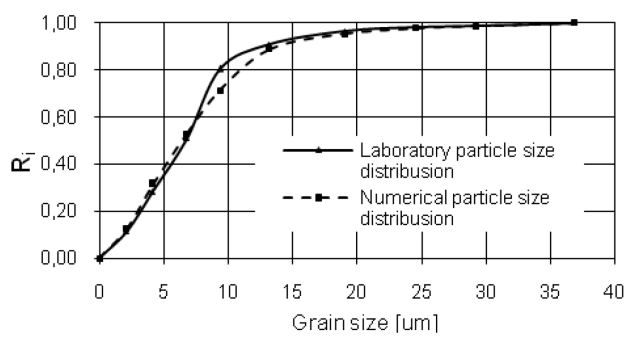

Fig. 3. As in Fig. 2, but for $p=0.4 \mathrm{MPa}$. 


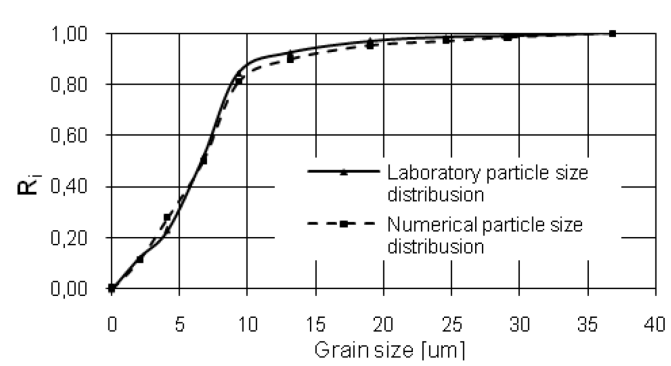

Fig. 4. As in Fig. 2, but for $p=0.5 \mathrm{MPa}$.

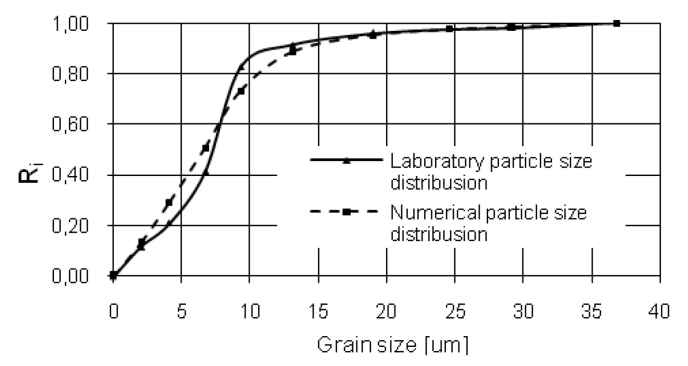

Fig. 5. Cumulative particle size distribution of grinding product technical chalk $(p=0.3 \mathrm{MPa}$, $\left.t=150^{\circ} \mathrm{C}\right)$.

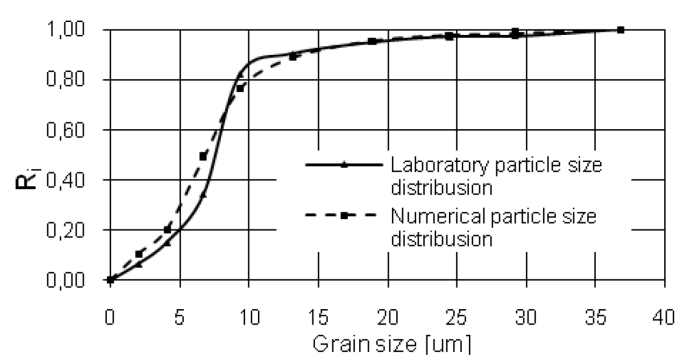

Fig. 6. As in Fig. 5, but for $p=0.4 \mathrm{MPa}$.

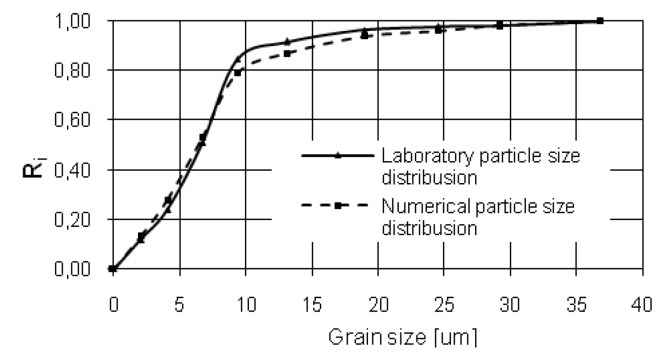

Fig. 7. As in Fig. 5, but for $p=0.5 \mathrm{MPa}$.

\section{Conclusions}

Based on the results of experimental tests and numerical determinations, it can be stated:

1. The cumulative grain distribution of the technical chalk jet grinding product can be determined numerically, knowing the values of the relevant physical quantities characterizing this type of grinding.
2. The presented model allows achieving results in accordance with laboratory determinations, regardless of the value of the parameters of the grinding process.

3. Numerical determinations of the granular distribution of the grinding product allow to eliminate time-consuming and costly laboratory granular analyzes.

\section{References}

[1] R. Siuda, J. Kwiatek, A. Obraniak, T. Gluba, T.P. Olejnik, A. MarszałekGubiec, T. Pietrasik, Przemyst Chemiczny 97, 1549 (2018) (in Polish).

[2] A. Obraniak, M. Orczykowska, T.P. Olejnik, Powder Technol. 342, 328 (2019).

[3] B. Kosturkiewicz, A. Janewicz, M. Hryniewicz, PrzemystChemiczny 96, 1873 (2017) (in Polish).

[4] D. Urbaniak, T. Wyleciał, V.P. Zhukov, E.V. Barochkin, Zeszyty Naukowe Politechniki Rzeszowskiej. Mechanika 2, 277 (2014) (in Polish).

[5] D. Urbaniak, E. Mielczarek, Archiv. Min. Sci. 44, 351 (1999).

[6] D. Urbaniak, Ph.D. Thesis, Częstochowa University of Technology, Częstochowa 2000.

[7] E. Mielczarek, D. Urbaniak, T. Wyleciał, Zeszyty Naukowe Politechniki Eódzkiej. Inżynieria Chemiczna i Procesowa 27, 189 (2000) (in Polish).

[8] W. Tomassi, H. Jankowska, Chemia Fizyczna, WNT, Warszawa 1973 (in Polish).

[9] E. Mielczarek, Archiwum Budowy Maszyn 28, 145 (1981) (in Polish).

[10] S. Ochęduszko, Termodynamika Stosowana, WNT, Warszawa 1974 (in Polish).

[11] Polish Norm PN/Z-04008, "Grain Analysis of Dust of Diameter less than $63 \mu \mathrm{m}$ " (in Polish). 